\title{
ERRATA
}

\section{Comparison of Verification Procedures for the Membrane Filter Total Coliform Technique}

\author{
MARK W. LECHEVALLIER, SUSAN C. CAMERON, AND GORDON A. McFETERS \\ Department of Microbiology, Montana State University, Bozeman, Montana 59717
}

Volume 45, no. 3, p. 1127, colun.n 1, paragraph 2, line 15: “0.75 M” should read “ 0.0166 M.”

\section{Influence of Substratum Wettability on Attachment of Freshwater Bacteria to Solid Surfaces}

\author{
JAMES H. PRINGLE AND MADILYN FLETCHER
}

Department of Environmental Sciences, University of Warwick, Coventry CV4 7AL, England

Volume 45 , no. 3, p. 811 , column 2, paragraph 2, lines 2 and 3: "formation" should read "adsorption."

Page 811 , column 2, paragraph 2, line 4: "relatively hygenic" should read "chemically clean." Page 812, column 2, paragraph 3, lines 9 and 10: "tissue culture-treated" should read "tissue culture."

Page 812, column 2, paragraph 3, line 16: "adsorption" should read "absorption."

Page 812, column 2, paragraph 4, line 5: "tissue culture-treated" should read "tissue culture." Page 813, Table 2, second column: "60" should read " 54 ."

Page 813, Table 2, footnote $a$ : "Standard deviation - 1" should read "Standard deviation."

Page 813, column 1, line 17: "filters" should read "fillers."

Page 814, column 1, Results, line 15: “(6)" should read "(17)."

Page 814, column 1, Results, line 19: "primary" should read "primarily."

Page 814, column 2, paragraph 2, line 10: "(15)" should read "(28)."

Page 814, column 2, paragraph 2, line 15: " $\theta_{E} \simeq \theta_{E}$ " should read " $\theta_{A} \simeq \theta_{E}$."

Page 815, column 2, lines 18 and 19: "nonpolar, and hydrogen bonding" should read "nonpolar, polar, and hydrogen bonding."

Page 817, column 1: reference 12 should read: "Fletcher, M., and G. I. Loeb. 1976. The influence of substratum surface properties on the attachment of a marine bacterium, p. 459-469. In M. Kerker (ed.), Colloid and interface science, vol. 3. Academic Press, Inc., New York." 